\title{
A Transcriptional Regulator of the LuxR-UhpA Family, FlcA, Controls Flocculation and Wheat Root Surface Colonization by Azospirillum brasilense Sp7
}

\author{
Lily Pereg-Gerk, ${ }^{1,2}$ Annick Paquelin, ${ }^{1}$ Pierre Gounon, ${ }^{3}$ Ivan R. Kennedy, ${ }^{2}$ and Claudine Elmerich ${ }^{1}$ \\ ${ }^{1}$ Unité de Physiologie Cellulaire, URA 1300 CNRS, Département des Biotechnologies, Institut Pasteur, \\ 28 rue du Docteur Roux, 75724 Paris Cedex 15, France; ${ }^{2}$ Sydney University Nitrogen Fixation Centre \\ (SUNFix), Department of Agricultural Chemistry and Soil Science, University of Sydney, NSW 2006, \\ Australia; ${ }^{3}$ Station Centrale de Microscopie Electronique, Département de Physiopathologie, Institut \\ Pasteur, 28 rue du Docteur Roux, 75724 Paris Cedex 15, France \\ Accepted 18 November 1997.
}

Genetic complementation of a spontaneous mutant, impaired in flocculation, Congo red binding, and colonization of root surface, led to the identification of a new regulatory gene in Azospirillum brasilense Sp7, designated flc $A$. The deduced amino acid sequence of flcA shared high similarity with a family of transcriptional activators of the LuxR-UhpA family. The most significant match was with the AgmR protein, an activator for glycerol metabolism in Pseudomonas aeruginosa. Derivatives of $\mathrm{Sp} 7 \mathrm{re}$ sulting from site-directed Tn5 mutagenesis in the flcA coding sequence were constructed by marker exchange. Characterization of the resulting mutant strains showed that $f l c A$ controls the production of capsular polysaccharides, the flocculation process in culture, and the colonization of the root surface of wheat. This study provides new information on the genetic control of the mechanism of plant root colonization by Azospirillum.

Azospirillum brasilense are free-living, nitrogen-fixing, aerobic, chemoorganotrophic bacteria that associate with a large number of plants, including forage and cereal crops (Okon 1994). The colonization process has been investigated (for reviews see Michiels et al. 1989b; Elmerich et al. 1992; Kennedy and Tchan 1992; Vande Broek and Vanderleyden 1995). Attachment of the bacteria to the root surface is a twostep process: a rapid and reversible adsorption onto the root system, followed by irreversible anchoring of the bacteria (Michiels et al. 1991). Adsorption is due to the polar flagellum of the bacteria, which is glycosylated and is considered to be an adhesin (Croes et al. 1993). Anchoring is due to the synthesis of fibrillar material consisting of bacterial polysaccharides and glycoproteins (for review see Del Gallo and Fendrik 1994). The exact composition and structure of Azospirillum capsular and extracellular polysaccharides (EPS) are still unknown. These polysaccharides are fluorescent in the pres-

Corresponding author: Claudine Elmerich; E-mail: elmerich@pasteur.fr

Nucleotide sequence data are to be found at the EMBL data base under accession number Y12363. ence of Calcofluor white and bind Congo red, suggesting the presence of cellulosic 1,4 $\beta$-glucans (Bastarrachea et al. 1988; Del Gallo et al. 1989; Michiels et al. 1990). They can bind plant lectins and may therefore contribute to adhesion to root surfaces (Del Gallo et al. 1989). Several Azospirillum exo-like genes have been identified by complementation of Rhizobium meliloti exo mutant strains impaired in synthesis of succinoglycan (Vande Broek and Vanderleyden 1995). Two of these, called $e x o B$ - and $e x o C$-correcting loci, have been localized on the p90 megaplasmid of $A$. brasilense $\mathrm{Sp} 7$ (Michiels et al. 1989a). exoB encodes a UDP-glucose $4^{\prime}$-epimerase. Azospirillum exoB- and exoC-correcting loci mutants are not affected in root attachment or colonization (Vande Broek and Vanderleyden 1995).

Pleiotropic mutants impaired in EPS synthesis, flocculation, and cyst formation have been obtained, but not genetically characterized (Michiels et al. 1990; Vande Broek and Vanderleyden 1995). The formation of cystlike structures, which might be functionally analogous to Azotobacter cysts (and will be referred as "cysts" in this paper), has been commonly observed in Azospirillum in old cultures (Sadasivan and Neyra 1985). Azospirillum cysts are ovoid and larger than vegetative cells, nonmotile because they are devoid of flagella, and contain large, poly- $\beta$-hydroxybutyrate granules. In liquid cultures, when fructose or $\beta$-hydroxybutyrate is the carbon source, cells aggregate into macroscopic clumps and flocculate (Sadasivan and Neyra 1985; Bleakley et al. 1988). Flocculation may be regarded as a nonproliferating, differentiated state.

In a previous work we have reported the properties of a spontaneous mutant of A. brasilense Sp7, designated Sp7-S (Katupitiya et al. 1995a), that did not bind Congo red, did not flocculate, lacked capsular polysaccharides, did not form cysts, and remained in the vegetative state when associated with wheat roots. The wild-type $\mathrm{Sp} 7$ colonized extensively the surface of the roots (Arsène et al. 1994), whereas the mutant strain Sp7-S colonized significantly only the sites of lateral root emergence, root crevices, and occasionally the internal tissues of the roots (Katupitiya et al. 1995a). To characterize the genetic defect(s) of Sp7-S, a gene bank of strain Sp7 was introduced by conjugation into $\mathrm{Sp7}-\mathrm{S}$ and a plasmid clone, termed pAB1220-9, that restored Congo red binding and floc- 
culation to Sp7-S was isolated (Katupitiya et al. 1995a). We report here the genetic characterization of the complementing region and the identification of a new regulatory gene, termed flcA. We also show that the Sp7-S phenotype resulted from multiple mutations. Insertion mutations in $f l c A$ were obtained, and analysis of the capsular material of the wild-type and mutant strains was studied by transmission electron microscopy (TEM) with thin sections of flocculated and nonflocculating cultures. The same regulatory $f l c A$ gene is involved in differentiation of bacteria either in the free-living state when they flocculate or in association with the host wheat plant when they colonize the root surface.

\section{RESULTS}

\section{Identification of a DNA locus responsible}

\section{for Congo red binding and flocculation in A. brasilense} and $A$. lipoferum strains.

The plasmid clone, pAB1220-9, (Fig. 1) that restored flocculation and Congo red binding to Sp7-S was introduced in different $A$. brasilense and A. lipoferum strains from our collection that differed in their ability to bind Congo red. The list of strains used is shown in Table 1. As reported in Table 2, strains Sp6 and Sp35 from A. brasilense and RG20, S28, and Br17 from A. lipoferum were impaired in staining with Congo red and in flocculation in the presence of fructose. Strain $\mathrm{Br} 17$ flocculated when the carbon source was $\beta$-hydroxybutyrate. Interestingly, in all cases, introduction of pAB1220-9 restored Congo red staining and flocculation in the presence of fructose, except for $\mathrm{Sp} 35$.

Derivatives of pAB1220-9 or 1220-9a carrying deletions of the internal PstI fragments (pAB1220-9b and pAB1220-9c) did not complement strain Sp7-S, while plasmid pAB2053 carrying a $B g l \mathrm{II}-\mathrm{Bam} \mathrm{HI}$ fragment, containing the $1.7-\mathrm{kb}$ and 1.1-kb PstI fragments, did so (Fig. 1). The 1.1-kb PstI fragment subcloned into pAB2051 was sufficient to restore Congo red staining and flocculation in the presence of both fructose and $\beta$-hydroxybutyrate. In addition, the only $\operatorname{Tn} 5$ insertions that abolished complementation by pAB1220-9a were localized into the 1.1-kb PstI fragment as shown in Figure 1 (T1, $\mathrm{T} 2$, and T4), while Tn5 insertions $\mathrm{T} 11$ and 12 did not. pAB2051 also restored flocculation in fructose-containing medium and Congo red staining to Br17 strain.

Floc formation has been described as optimal when fructose was the carbon source with low $\mathrm{KNO}_{3}$ concentration (0.5 $\mathrm{mM}$ ), although it also occurred at higher concentrations (Sadasivan and Neyra 1985). We then checked whether some of the regulatory mutants of our collection impaired in regulation of nitrogen fixation or nitrate utilization were impaired in their properties to flocculate. Flocculation was observed for $n t r C$, nifA, and $g \ln B$ mutant strains (de Zamaroczy et al. 1993, and references therein) in the presence of fructose and nitrate or fructose and ammonia, and all bind Congo red. An rpoNlike mutant strain (C. Elmerich, L. Pereg-Gerk, and A. Paquelin, unpublished) also behaves in the same way as the wild type (data not shown).

Establishment of the nucleotide sequence of the complementing fragment and identification of an ORF showing similarity with the LuxR-UhpA regulator family.

When the 1.1-kb PstI complementing fragment in pAB2051 was subcloned in the opposite orientation (pAB2051b), no complementation of Sp7-S was observed, suggesting that in pAB2051 the gene was incomplete. The nucleotide sequence

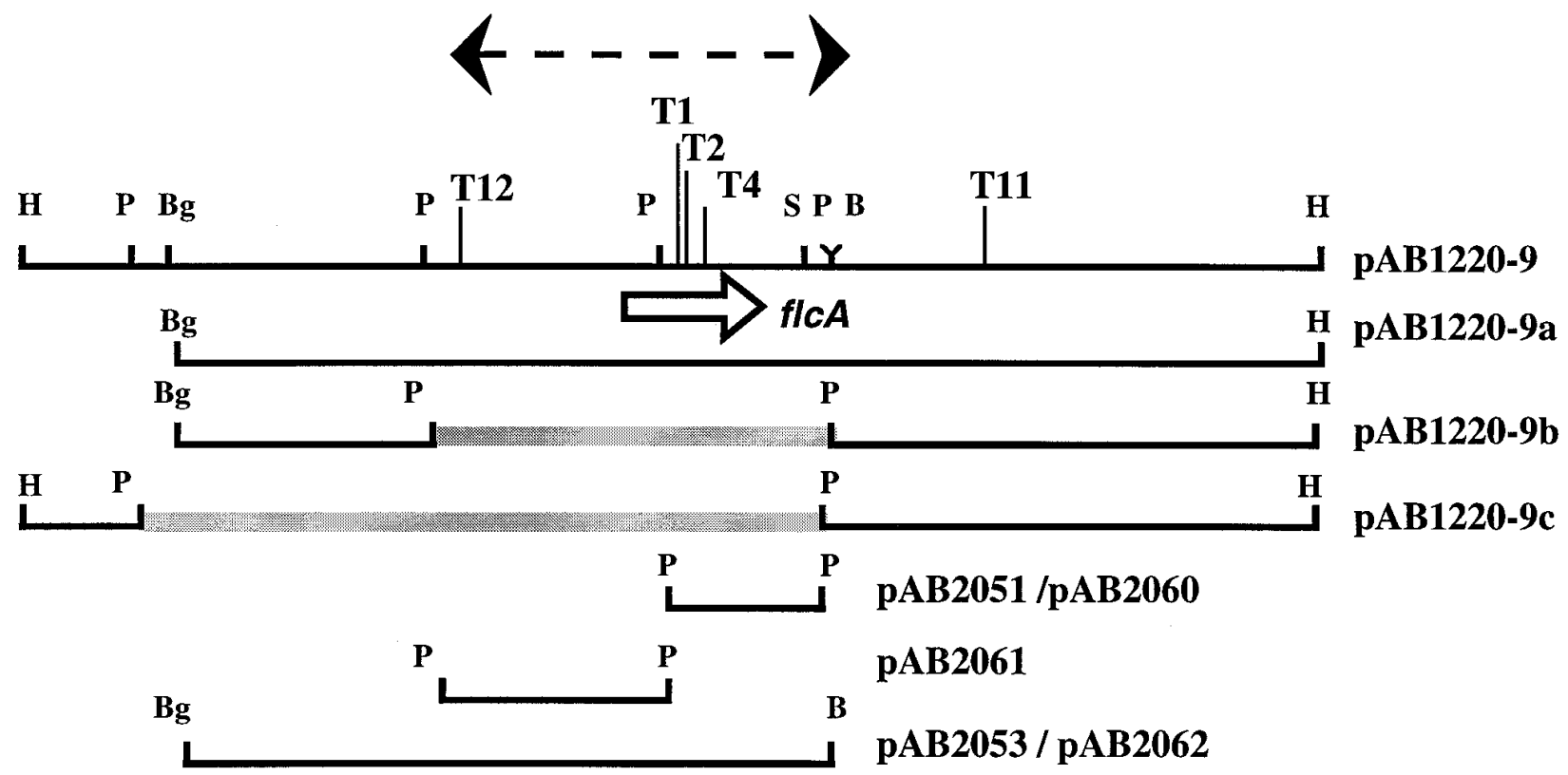

1 kb

Fig. 1. Schematic representation of physical map of flcA region and of relevant plasmid inserts. Restriction sites: B, BamHI; Bg, BglII; H, HindIII; P, PstI; S, SalI. Localization and orientation of the open reading frame $f l c A$ is indicated by the arrow; the DNA region sequenced is indicated between the double arrowheads. Plasmid vectors are not shown; deleted regions are shown as dotted boxes. pAB-1220-9, -9a, -9b, -9c inserts as well as pAB2051 and -2053 are in broad host range IncP vectors and were used in complementation studies. pAB2060, -2061- and -2062 are pTZ18R derivatives that were used for the establishment of the nucleotide sequence. 
of a 2,518-bp fragment, covering most of the 1.7-kb PstI fragment and the adjacent $1.1-\mathrm{kb} P s t \mathrm{I}$ and Pst I-BamHI fragments, was established. Sequencing of the flanking regions of $\mathrm{Tn} 5$ insertions $\mathrm{T} 1$ and $\mathrm{T} 4$ was performed to identify the correct open reading frame (ORF). A putative ORF, from positions 1238 to 1883 , encoding a polypeptide of 215 amino acids of 22,840 Da, designated flcA, was found. The deduced amino acid sequence of $f l c A$ (FlcA) shares high identity with a large number of transcriptional regulators belonging to the LuxR/UhpA family (Gross et al. 1989; Henikoff et al. 1990). Among those are the following: Bacillus subtilis DegU (P13800), GerE (P11470); Escherichia coli NarP (P31802), NarL (P10957), and UhpA (P10940); and R. meliloti FixJ (P10958) (see Stock et al. 1989; Msadek et al. 1993). The most significant match was with the regulator AgmR (P29369), an activator for glycerol metabolism in Pseudomonas aeruginosa (Schweizer 1991); it showed 35\% identity and 55\% similarity over the 207 amino acids of FlcA. A sequence alignment of FlcA with the $P$ aeruginosa AgmR and B. subtilis DegU effector proteins (Fig. 2) shows that they share homology both in their first 130 amino acids and in their carboxy terminal. This homology includes three conserved aspartic acid residues $(7,8$, and 54 of FlcA) and a conserved lysine (104 of FlcA) usually conserved in response regulators (Stock et al. 1989) as well as a region corresponding to amino acid residues 170 to 192 , which was significantly similar to an helix-turn-helix motif (Kahn and Ditta 1991).

Analysis of the DNA region preceding $f l c A$ did not reveal the presence of any ORF sharing significant similarity with data banks, suggesting that flcA may not be part of a twocomponent system. Downstream of flcA, at position 2080, an incomplete ORF encoding a polypeptide of 146 amino acids showed high identity (46\% on a 143-amino acid-overlap) with an unknown protein of Mycobacterium tuberculosis (PIDe276870) and other related proteins (data not shown).

Phenotypic characterization of $f l c A$-Tn 5 -induced mutants. Mutants of strain Sp7 carrying the Tn5 insertions T1, T2, and $\mathrm{T} 4$ in the $f l c A$ region, recombined at the correct location, were isolated as described in Materials and Methods. The resulting mutant strains, 72001, 72002, and 72004, respectively, did not stain with Congo red or flocculate in fructose- or $\beta$ hydroxybutyrate-containing media. The mutant strains did not lose their motility even after $72 \mathrm{~h}$ of incubation in the flocculation medium, in contrast to the wild-type Sp7. A major difference was observed between $\mathrm{Sp} 7-\mathrm{S}$ and the Tn5 insertion

Table 1. Bacterial strains and plasmids

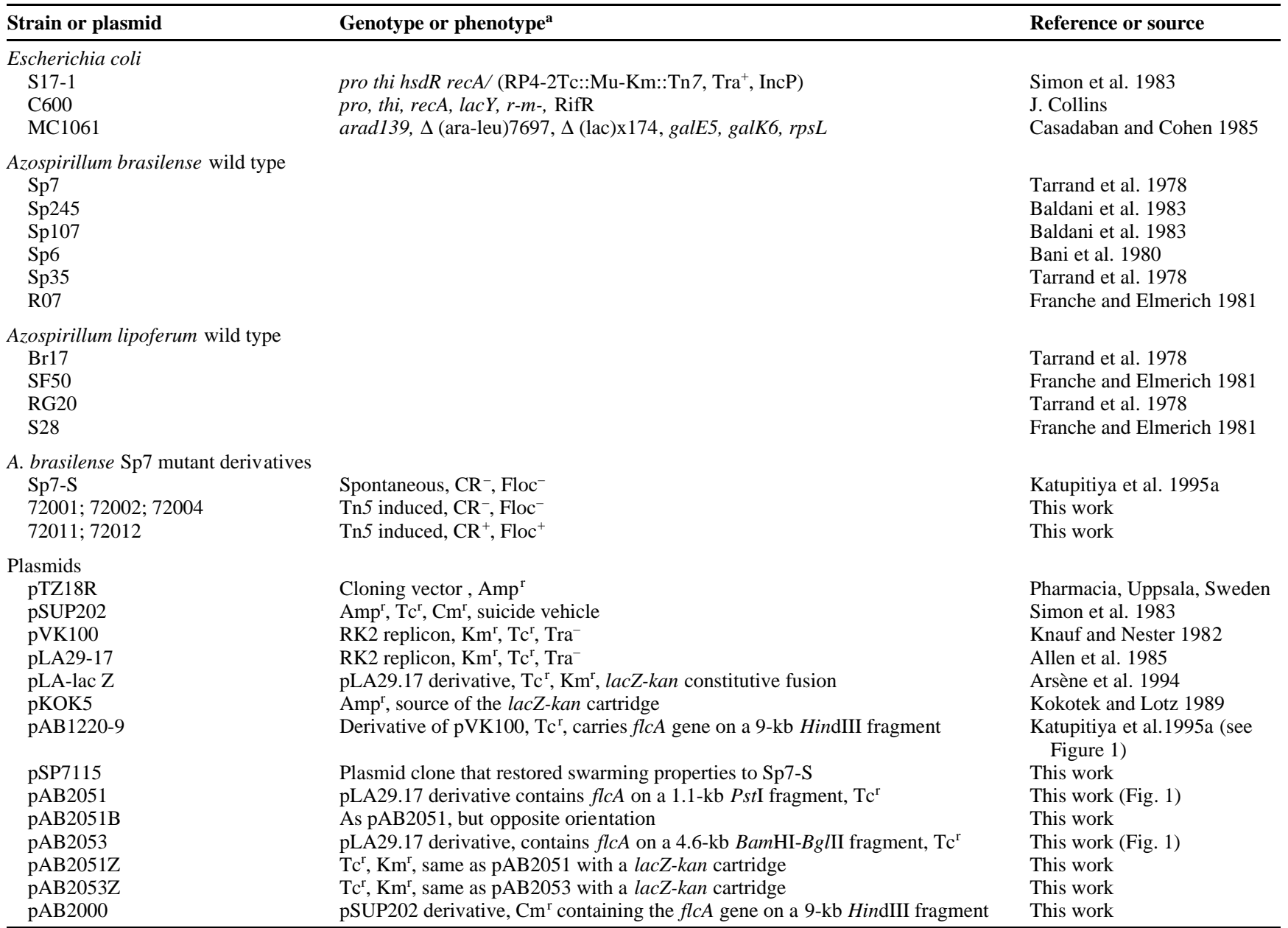

${ }^{a} \mathrm{Amp}^{\mathrm{r}}, \mathrm{Cm}^{\mathrm{r}}, \mathrm{Km}^{\mathrm{r}}, \mathrm{Tc}^{\mathrm{r}}$ indicate resistance to ampicillin, chloramphenicol, kanamycin, and tetracycline, respectively; kb, kilobase; CR, Congo red binding; Floc, flocculation. 
mutants, since Sp7-S forms smaller and less mucoid colonies than the wild type, while colonies of the Tn5 mutants had the same size and mucoid appearance as those of the wild type. The difference in size could be due to different ability to spread on solid surface, and hence to a defect in Sp7-S motility. All strains were motile in liquid media, but in semisolid

Table 2. Congo red binding and flocculation ability of Azospirillum strains

\begin{tabular}{|c|c|c|c|}
\hline \multirow[b]{2}{*}{ Strain $^{\mathrm{a}}$} & \multirow[b]{2}{*}{$\begin{array}{c}\text { Congo red } \\
\text { binding }^{\mathbf{b}}\end{array}$} & \multicolumn{2}{|c|}{$\begin{array}{c}\text { Flocculation } \\
\text { substrate }^{\mathbf{c}}\end{array}$} \\
\hline & & Fructose & $\begin{array}{c}\beta \text {-hydroxy- } \\
\text { butyrate }\end{array}$ \\
\hline \multicolumn{4}{|l|}{ Azospirillum brasilense } \\
\hline Sp7 & + & + & + \\
\hline Sp7-S & - & - & - \\
\hline Sp7-S (pAB1220-9 or pAB2051) & + & + & + \\
\hline Sp6 & - & - & $\mathrm{NT}^{\mathrm{d}}$ \\
\hline Sp6 (pAB1220-9) & + & \pm & NT \\
\hline $\mathrm{Sp} 35$ & - & - & NT \\
\hline Sp35 (pAB1220-9) & + & - & NT \\
\hline Sp107; R07 & + & + & NT \\
\hline Sp245 & + & + & + \\
\hline \multicolumn{4}{|l|}{ Azospirillum lipoferum } \\
\hline SF50 & + & + & NT \\
\hline RG20; S28 & - & - & NT \\
\hline RG20 or S28 (pAB1220-9) & + & + & NT \\
\hline Br17 & - & - & + \\
\hline $\mathrm{Br} 17$ (pAB1220-9 or $\mathrm{pAB} 2051)$ & + & + & NT \\
\hline \multicolumn{4}{|c|}{$\begin{array}{l}\text { a Introduction of the plasmid vector pVK } 100 \text { in the strains did not mod- } \\
\text { ify the Congo red binding ability or the flocculation properties. } \\
\text { b Congo red was added to minimal lactate solid medium in a final con- } \\
\text { centration of } 40 \mu \mathrm{g} / \mathrm{ml} \text {. Plates were incubated for } 3 \text { days at } 30^{\circ} \mathrm{C} \text {. } \\
\mathrm{c} \text { Flocculation was studied with minimal liquid medium in the presence } \\
\text { of } 0.5 \mathrm{mM} \mathrm{KNO} \mathrm{KN}_{3} \text { and either } 8 \mathrm{mM} \text { fructose or } 20 \mathrm{mM} \beta \text {-hydroxy- } \\
\text { butyrate. }\end{array}$} \\
\hline
\end{tabular}

agar the spreading of Sp7-S was reduced (50\%), compared with the wild type and Tn 5 mutants. Other phenotypic properties examined were identical to those of the wild type. The growth rate in the presence of ammonia was identical to that of the wild type. The nitrogenase activity was comparable and the mutants can use nitrate as a nitrogen source. Utilization of malate, lactate, gluconate, glycerol, or $\beta$-hydroxybutyrate as a sole carbon source was comparable to the wild type, and similarly the mutants grew poorly on galactose or fructose.

It was verified that introduction of plasmids pAB2053 and pAB2051 restored both flocculation and Congo red staining to the Tn5 mutants and Sp7-S. None of the plasmids restored swarming mobility, nor normal colony size, to Sp7-S, suggesting that Sp7-S carried another mutation responsible for that phenotype. Indeed, from a gene bank of Sp7 DNA fragments (Zimmer et al. 1995), it was possible to isolate another plasmid clone, termed pSP7115, that restored full swarming property to Sp7-S. This plasmid had a different physical map from pAB1220-9 and did not complement the flocculation defect.

Tn5 insertions T11 and T12, located on both sides of the DNA region involved in the flocculation and the Congo red binding, were recombined into $\mathrm{Sp} 7$. The resulting strains 72011 and Sp72012 did not differ from the wild type.

\section{Cytology of flocculating and nonflocculating cells.}

The flocculation process was studied after 1, 2, 4, 6, and 24 $\mathrm{h}$ of incubation, with vigorous shaking at $30^{\circ} \mathrm{C}$, in the fructose-containing medium. In general, with the wild-type $\mathrm{Sp} 7$, the production of flocs that are visible with the naked eye starts after 3 to $4 \mathrm{~h}$ of incubation, and after 6 to $7 \mathrm{~h}$ the flocs increased to the maximal size. Examination of thin sections by electron microscopy of the flocculated (Fig. 3B, C, D) and nonflocculated cultures of the wild type (Fig. 3A) revealed important differences in the ultrastructure, as previously reported (Sadasivan and Neyra 1985, 1987). A comparison was

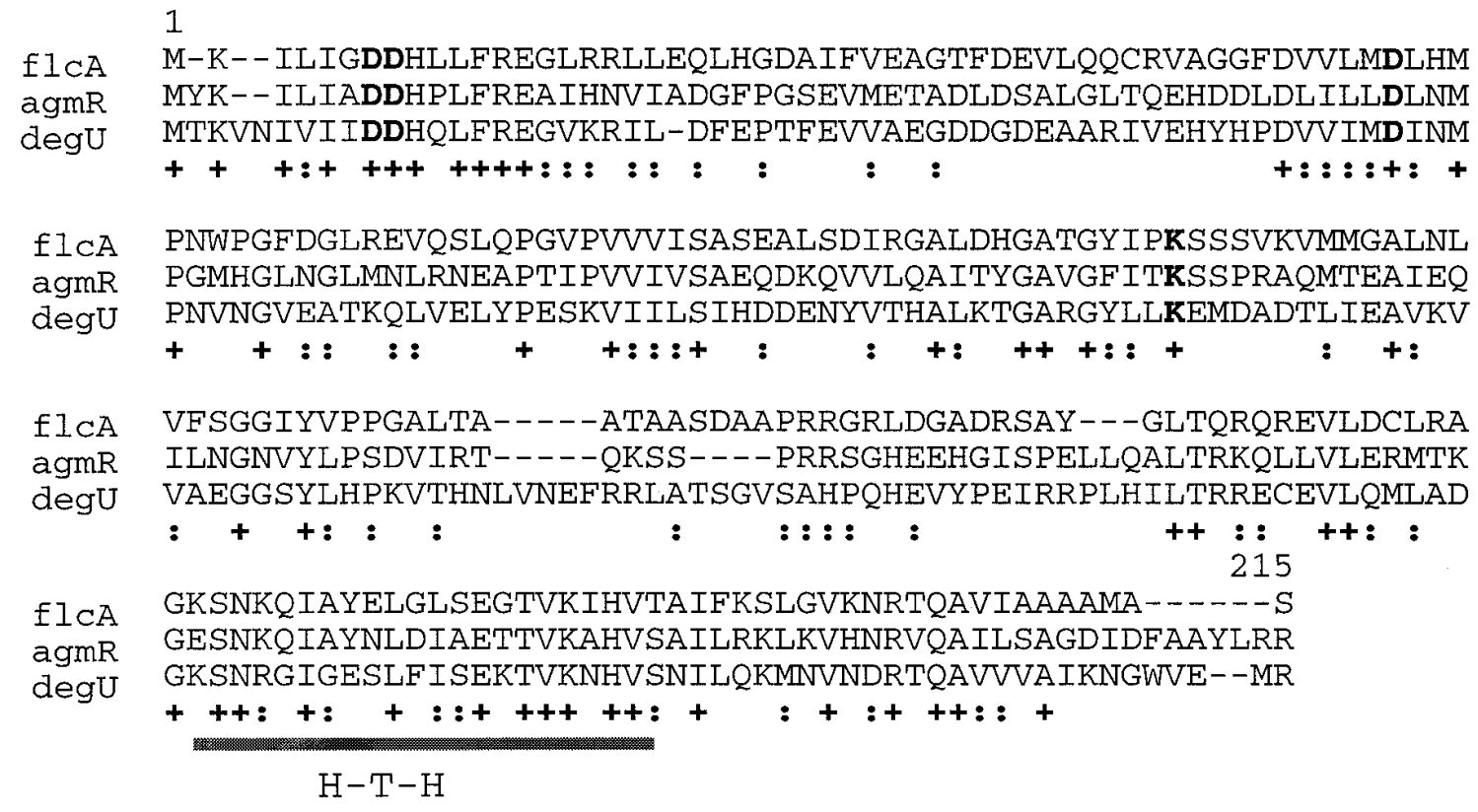

Fig. 2. Comparison of the deduced amino acid sequence of FlcA with that of AgmR and DegU. (+) indicates residues that are identical, (:) indicates residues that have similar chemical properties (ILMV, AGPST, DENQ, and HKR, FY). D and K residues conserved in response regulators are indicated in bold. Potential helix-turn-helix motif is underlined. 
made with the nonflocculating mutant strains 72001 (Fig. 4A, B), 72002, and Sp7-S (not shown) to establish which morphological changes were controlled by the $f l c A$ gene. After $1 \mathrm{~h}$ of incubation in fructose-containing media, no major differences between cultures of wild type (Fig. 3A) and mutants (Fig. 4A) was observed, when comparing the ultrastructure of bacteria at the time of inoculation or during the exponential phase in rich medium or in lactate ammonia medium (data not shown).

With the wild-type strains after $2 \mathrm{~h}$ of incubation in the fructose-containing medium, one starts to see cell aggregation, and this is much more exemplified, as shown in Figure 3B, after $4 \mathrm{~h}$. In addition, at $4 \mathrm{~h}$ a major change is visible in the ultrastructure of the cell wall with a thickening of the outer coat. At $6 \mathrm{~h}$, accumulation of poly- $\beta$-hydroxybutyrate granules and the production of a polysaccharide net start to be visible. The cells progressively lose their motility, and they turn to a more ovoid shape. After $24 \mathrm{~h}$ of incubation, the cells are completely embedded in a dense capsular meshwork.
With the mutant strains (Fig 4B) the only remarkable change after $24 \mathrm{~h}$ of incubation in the flocculation medium was the accumulation of poly- $\beta$-hydroxybutyrate granules and of brown-pigmented, melaninlike granules, also observed with the wild type. Thus, the accumulation of these granules is not controlled by flcA, while other traits described above are.

\section{In situ detection of bacteria on wheat roots by $\mathrm{X}$-Gal staining and estimation of the efficiency of colonization. \\ Colonization of wheat roots was studied by inoculation of} wild-type and Tn5-induced nonflocculating mutants containing a plasmid with a constitutive lacZ fusion, pLA-lacZ. Strain Sp7-S containing the same plasmid was used as a control. The extent of colonization was estimated after coloration with X-Gal, 10 days after inoculation of the wheat roots (Arsène et al. 1994). This enabled examination of the spatial distribution of the bacteria and revealed differences between the pattern of colonization by the wild-type and mutant strains. As reported previously (Arsène et al. 1994; Vande
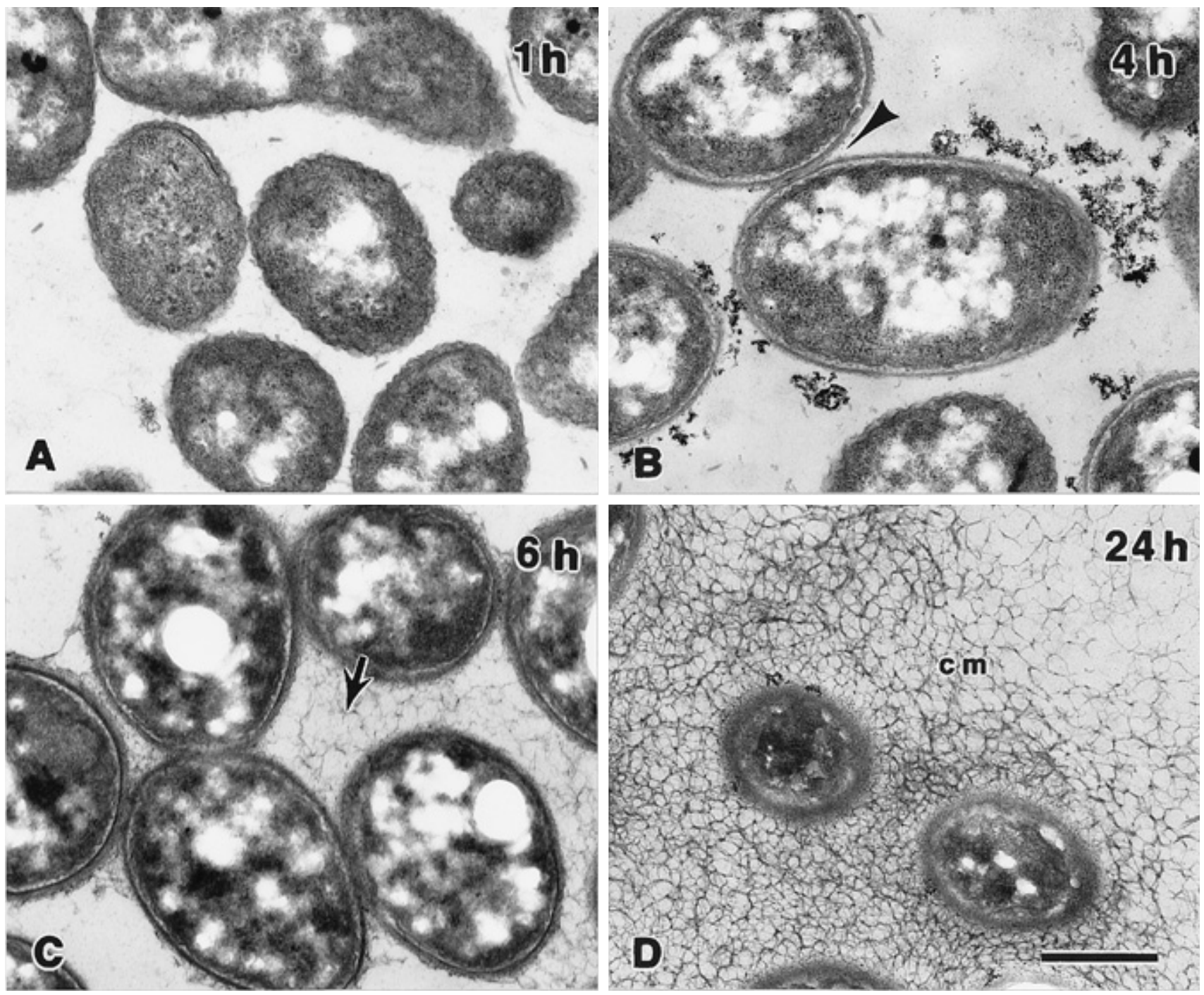

Fig. 3. Electron micrograph of thin sections of Azospirillum brasilense wild-type strain (Sp7) incubated in fructose-containing medium during flocculation process. After 1 (A) or $2 \mathrm{~h}$ (not shown), most bacteria were free and flagellated. After $4 \mathrm{~h}$, bacteria began to stick together (B, arrowhead). After $6 \mathrm{~h}$ of incubation, number of bacteria involved in the flocs increased dramatically; there is a thickening of the cell wall outer coat as well as a fine capsular meshwork (cm). Two major features of the flocs, thick outer coat and capsular meshwork, were maximum after $24 \mathrm{~h}$ of incubation. $($ Bar $=0.5 \mu \mathrm{m}$.) 
Broek et al. 1993), plants treated with Azospirillum wild-type strains Sp7 and Sp245 showed heavy root surface colonization, especially in the lower part of the roots. Colonization of the crevices surrounding the sites of lateral root emergence and the area of dense root hair near the root tip was also important. The data observed with the Tn5 insertion mutants were consistent with the previous observations made with Sp7-S (Katupitiya et al. 1995a). A strongly reduced amount of coloration was detected in roots inoculated with $\mathrm{Sp7-S}$ or with the Tn5-induced mutants, 72001, 72002, and 72004, as compared with that of roots inoculated with the wild-type Sp7. Bacteria were mostly located at the site of lateral root emergence and also they were embedded in the root hair near the root tip. An example of the root hair zone colonization with the wild type is shown in Figure 5E; similar pictures were observed with the mutant strains. The main difference between wild-type and mutant strains was in the extent of surface colonization, as illustrated in Figure 5B (see below). After 10 days of colonization with the wild type, a proportion of the bacteria were ovoid in shape, resembling the morphology typical of cystlike cells (Fig. 5C), while in plants treated with Sp7-S, 72001 (Fig. 5D), 72002, or 72004, the bacteria mostly retained a curved rod shape resembling vegetative azospirilla.

Restoration of surface colonization was observed when the mutant strains were complemented by pAB2053Z that carry the region that restored flocculation at the free-living state and a lac $Z$ fusion driven by a constitutive promoter. The ovoid morphology of the bacteria was also observed in the complemented samples. An example of the difference in surface colonization, in a zone located a few centimeters from the root

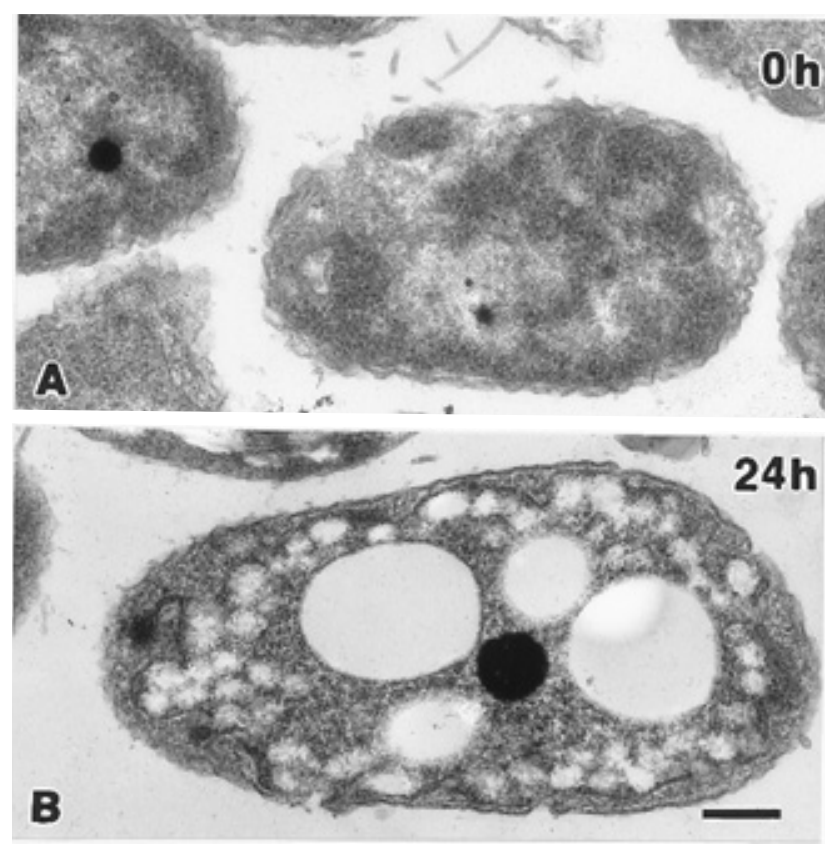

Fig. 4. Electron micrograph of thin sections of the nonflocculating mutant strain 72001 during incubation in fructose-containing medium. A, Time 0 . B, After $24 \mathrm{~h}$. There is no modification of the cell wall and no appearance of capsular meshwork. As in the wild-type strain, storing of poly- $\beta$-hydroxybutyrate inclusions and pseudo-melanin granules was observed after $24 \mathrm{~h}(\mathbf{B})$. (Bar $=0.5 \mu \mathrm{m}$.) No difference with 72001 was observed when comparing the ultrastructure of the mutant strain 72004 and $\mathrm{Sp} 7-\mathrm{S}$ incubated in similar conditions. tip, between 72004 containing pLA-lacZ and 72004 complemented with pAB2053Z, is shown in Figure 5B and A.

The relative efficiency of colonization of the wild type and the mutants was estimated by assaying $\beta$-galactosidase activity of root extracts inoculated with the wild type and mutants carrying either pLA-lacZ or pAB2053Z. In a previous work it was shown that there was a good correlation between the $\beta$ galactosidase activity and the number of bacteria associated with the root system estimated by the most probable number technique, and that the $l a c Z$ plasmids were stably maintained during the colonization process (Arsène et al. 1994). Data reported in Figure 6 reveal a reduced $\beta$-galactosidase activity with strain Sp7-S (lane B) and the Tn5 insertion mutants 72001 and 72002 (lanes D and F), in the range of 20\%, as compared with the wild type (lane A). This reflects a reduced number of bacteria associated with the root system, in agreement with the in situ coloration (shown in Figure 5), the decrease being essentially linked to the reduced surface colonization, while there is still a proportion of the bacteria embedded in the root hair zone. Introduction of the complementing plasmid pAB2053Z restored wild-type level of $\beta$ galactosidase activity in 72001 and 72004 (lanes E and G), suggesting full complementation of the mutant. Interestingly, complementation of Sp7-S with the same plasmid was only partial (lane C), which may account for the fact that Sp7-S differs from the wild type by more than one mutation.

\section{DISCUSSION}

Flocculation in A. brasilense $\mathrm{Sp} 7$ appears as the transformation of a vegetative cell within a few hours into a differentiated form, referred to here as a cyst. Interestingly, colonization of the root surface by the bacteria involves a morphological change reminiscent of the morphology of cysts. This work describes the identification of a new regulatory gene governing cellular differentiation in A. brasilense Sp7 and strongly affecting the pattern of root surface colonization.

The genetic analysis performed and the establishment of the nucleotide sequence of a $2.5-\mathrm{kb}$ fragment are consistent with the identification of a single gene, which we have designated $f l c A$. The deduced translation product of $f l c A$, of 215 amino acids, shares similarity to the C-terminal domain of a large number of transcriptional regulators of the LuxR-UhpA family. Most of these are response regulators (including DegU, FixJ, NarP), suggesting that FlcA could be part of a similar two-component regulatory system. Although the highest similarity was with AgmR, for which no second component was found, the absence of a coding sequence for a histidine kinase in the vicinity of $f l c A$ does not rule out the possibility that FlcA could be a part of a two-component regulatory system. The sensor component is not necessarily always part of the same transcriptional unit as the regulator and exceptions, such as $r \operatorname{cs} B-r c s C$ of $E$. coli (Stout and Gottesman 1990), have been documented. The LuxR family contains several transcriptional activators regulated by auto-induction, and no ORF encoding a regulatory protein of the LuxI type (Swift et al. 1993) was found in the vicinity of flcA. The 1.1-kb PstI fragment in pAB2051, which was sufficient to restore flocculation to the Tn5 mutants and Sp7-S, is deleted from the first 71 residues of the presumed translation product of $f l c A$. There are two ATG 100 bp downstream from the PstI site that could 

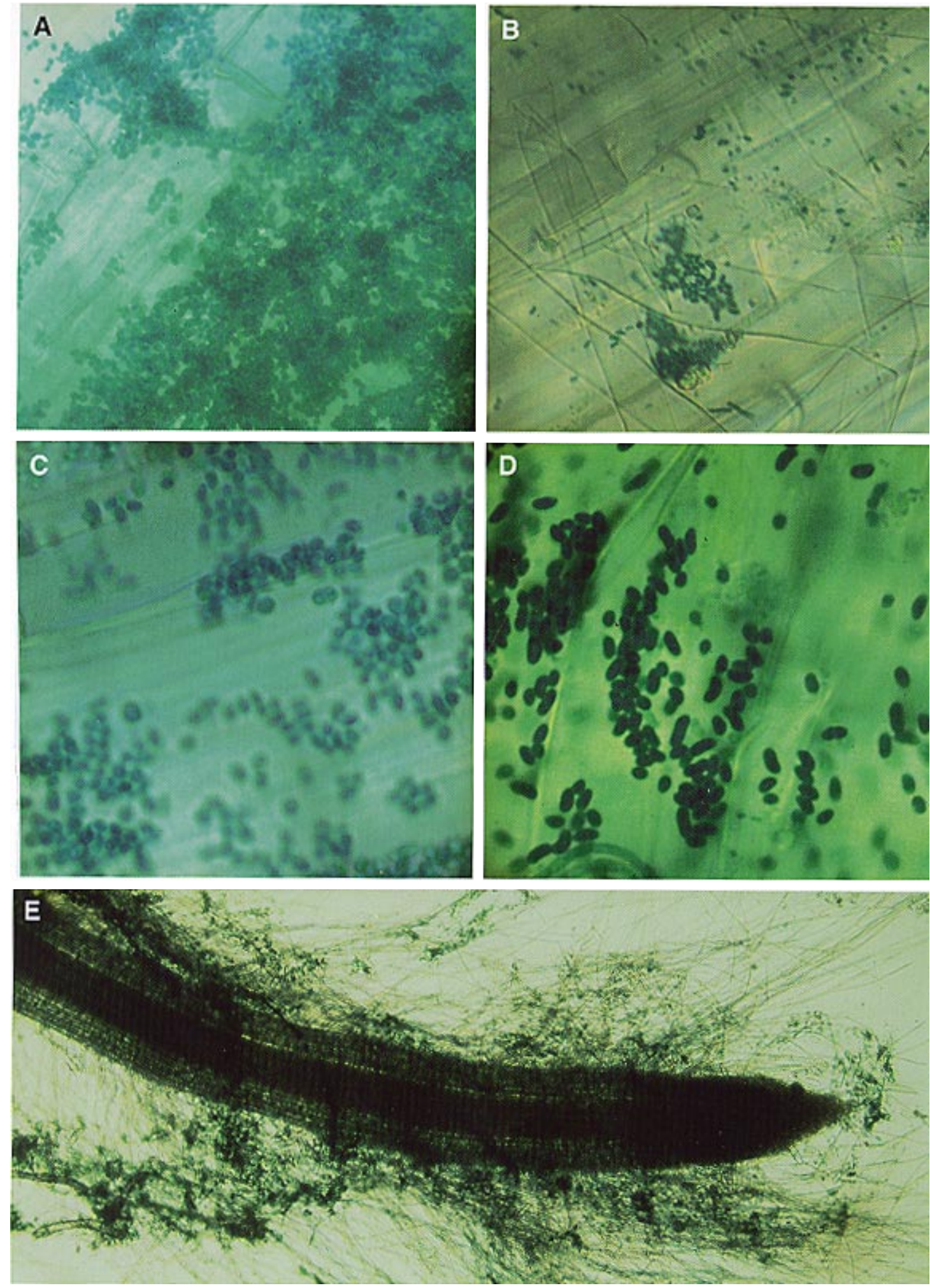

Fig. 5. Colonization of wheat root by the wild-type and mutant strains containing the lac $Z$ plasmid. Examples of difference in surface colonization between 72004 complemented by pAB2053Z (A) and 72004 (pLA-lacZ) (B). Example of difference in morphology between the wild type (C) and the mutant 72001(pLA-lacZ) (D). Example of colonization of the root hair zone by the wild-type Sp7(pLA-lacZ) (E). Magnification $\times 350(\mathbf{A}$ and $\mathbf{B}) ; \times 1,280$ $(\mathbf{C}$ and $\mathbf{D}) ; \times 35(\mathbf{E})$. 
serve as the potential initiation codon for a polypeptide of 105 residues containing the $\mathrm{C}$-terminal domain with its DNA binding region, and devoid of the Asp residues susceptible of phosphorylation. Indeed, transcriptional activators that consist entirely of the carboxy terminal domain of the response regulator, such as GerE of B. subtilis, were reported previously (reviewed in Msadek et al. 1993). However, it was assumed that the gene $f l c A$ is larger than 105 amino acids (i.e., 215 amino acids) since (i) similarity of the deduced amino acid sequence with the $\mathrm{N}$-terminal domain of other transcription regulator is significant, (ii) the Tn5 insertion $\mathrm{T} 1$ that abolished complementation is located at least 40 nucleotides upstream of these two ATG codons, and (iii) we have checked that the fusion of flcA and the aphII gene of vector (pLA29-17) at the PstI site was in frame. Thus, a truncated form of FlcA driven by the aphII promoter is sufficient to activate the target genes. This was described for FixJ, in which a truncated form of FixJ, FixJC, lacking 127 residues of the N-terminal part, was found to activate the transcription of its target gene nifA independently of FixL, its sensor component (Kahn and Ditta 1991).

The construction of strains isogenic to Sp7 carrying Tn5 insertion interrupting the $f l c A$ sequence indicated that the same gene is responsible for the differentiation during flocculation

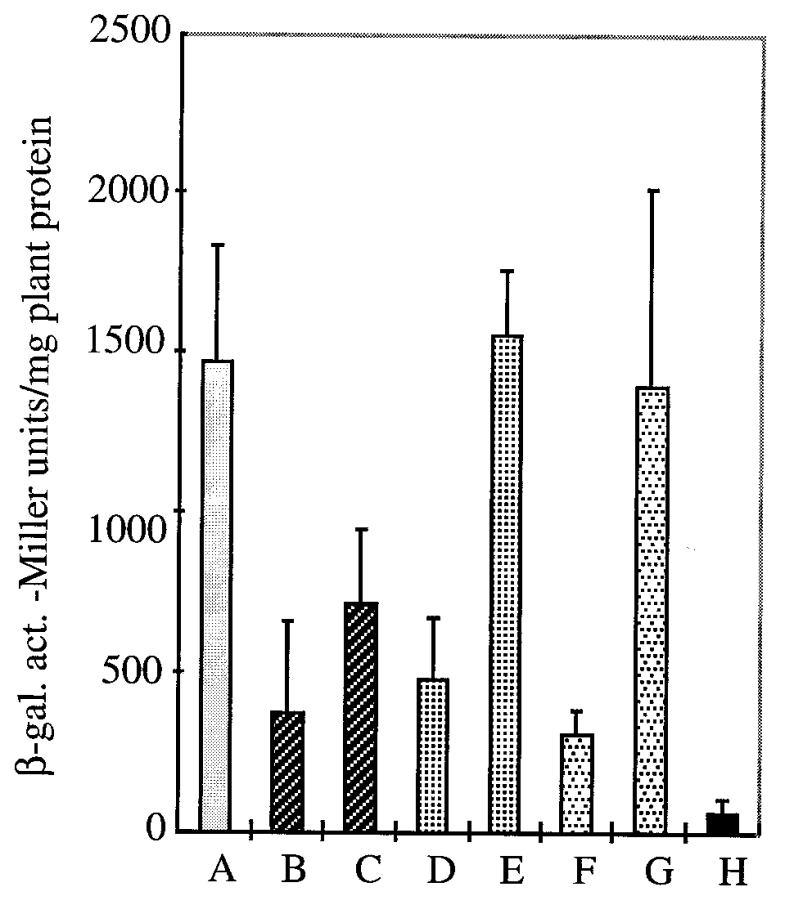

Fig. 6. $\beta$-galactosidase activity of plant extracts inoculated with Azospirillum brasilense $\mathrm{Sp} 7$ wild-type and mutant strains carrying either pLA-lacZ or pAB2053Z. One-week-old plantlets were inoculated with 5 $\times 10^{6}$ bacteria per $\mathrm{ml}$ of hydroponics. $\beta$-galactosidase activity was measured 10 days after inoculation and is expressed as Miller units per $\mathrm{mg}$ of plant protein. Data are the average of 10 determinations. pLAlac Z contains a constitutive lacZ fusion and pAB2053Z is a derivative of the plasmid pLA-lacZ containing the complementation region for flocculation. A, A. brasilense Sp7 (pLA-lacZ). B, Sp7-S, spontaneous mutant impaired in flocculation and Congo red binding (pLA-lacZ). C, Sp7-S (pAB2053Z). D, 72001, Tn5-induced, nonflocculating mutant of Sp7 (pLA-lacZ). E, 72001 (pAB2053Z). F, 72004 (pLA-lacZ). G, 72004 (pAB2053Z). H, Noninoculated control plant. and the reduced root surface colonization. However, we have no evidence that both cells are identical in their ultrastructure and physiology, yet. Analysis of the flocculation process by electron microscopy revealed important morphological changes between the wild type and flocculation mutants. From these studies it can be concluded that (i) flcA controls the aggregation of the cells, probably by controlling the production of lectinlike proteins (see Del Gallo et al. 1989), (ii) flcA controls the formation of the outer coat and capsular material and the secretion of polysaccharides to form a net surrounding the cells, and (iii), considering flocculation as a differentiation process, $f l c A$ is likely part of a complex regulatory cascade, probably controlling one of the early steps. None of the target genes is known, yet. However, flcA does not control the accumulation of PHB and brown-pigmented granules. The loss of motility linked to the loss of the polar flagellum is concomitant with the appearance of the capsular material and a more ovoid shape, but it cannot be concluded at this stage whether it is controlled by flcA or it is a consequence of the thickening of the cell wall. In association with roots, the $\operatorname{Tn} 5$ mutants presented a morphology resembling their vegetative form and this was correlated with a strong decrease of surface colonization. Indeed, the shape was different from the ovoid appearance of the wild type or of the complemented mutants and it resembled that previously observed with Sp7-S (Katupitiya et al. 1995a). It is thus tempting to conclude that flcA also controls differentiation in association with the plant. Further experiments are in progress to provide a better cytological comparison and a better localization of the wild type and the mutants on the root surface and in the superficial layer of the root cortex.

Using the spontaneous mutant $\mathrm{Sp7}$-S, a correlation was previously established between the production of capsular polysaccharides, flocculation, and root colonization, although this did not rule out the possibility of additional mutations responsible for the pleiotropic phenotype observed. The data reported here show that $\mathrm{Sp} 7-\mathrm{S}$ carries most likely a mutation in flcA and at least one additional mutation. The additional mutation impairs the spreading in semisolid agar at the freeliving state and it is also involved in colonization efficiency. The assumption that the additional mutation is also involved in colonization efficiency is based on the fact that the extent of the colonization of the root surface Sp7-S was not fully complemented by pAB2053Z (Fig. 6). A. brasilense is known to produce two types of flagella (Hall and Krieg 1983). A polar flagellum ensures its motility in liquid medium, and the synthesis of lateral flagella in semisolid agar contributes to the swarming motility. Mutants of the lateral flagella are not impaired in the attachment process (Moens et al. 1995), suggesting that only the polar flagellum is responsible for adsorption to the root system (Croes et al. 1993). Therefore, a working hypothesis is that Sp7-S synthesizes a polar flagellum deficient in adsorption. Further characterization of the complementing region on pSP7115 is in progress to identify the gene responsible for that phenotype.

The survey of several strains of $A$. brasilense and $A$. lipoferum from our collection revealed that many of them are impaired in their flocculation properties and ability to bind Congo red. This suggests that this genetic trait may not be very stable in Azospirillum. Interestingly, the plasmid that complements Sp7-S also complemented the deficient strains, 
with the exception of one, Sp35. It therefore appears that $f l c A$ might be one of the key genes of cellular differentiation, both in A. brasilense and A. lipoferum. Strain Br17 of A. lipoferum, which did not flocculate in the presence of fructose, was of particular interest because it appeared as one of the most efficient root colonizers on wheat, forming ovoid-shaped cells on the root surface (Katupitiya et al. 1995b). We show here that indeed the strain is capable of flocculation in the presence of $\beta$-hydroxybutyrate. Thus, in the free-living state the nature of the carbon source may be the main factor that induces flocculation. As the plants used for the colonization experiments are grown in hydroponics devoid of carbon and nitrogen sources, we assumed that the signal that activates FlcA, whatever the mechanism, is produced by the plant in the culture medium, or may result from a direct contact of the bacteria to the root surface (Dufrène et al. 1996), or both. Identification of the target genes controlled by $f l c A$ should help to document this hypothesis.

\section{MATERIALS AND METHODS}

Bacterial strains, plasmids, media, growth conditions, flocculation, nitrogenase assay, and conjugation.

The bacterial strains and most of the plasmids used in this work are listed in Table 1 and others are depicted in Figure 1. Plasmid pSP7115 was isolated from a gene bank of $A$. brasilense Sp7 prepared by Zimmer et al. (1995). Rich culture media was Luria-Bertani broth for E. coli and nutrient broth (Difco, Detroit, MI) for A. brasilense. Minimal medium containing $10 \mathrm{mM}$ lactate and $20 \mathrm{mM} \mathrm{NH}_{4} \mathrm{Cl}$ was as previously described (Galimand et al. 1989). Otherwise the concentration of sugar, organic acids, and glycerol was $10 \mathrm{mM}$. Congo red was added at a final concentration of $40 \mu \mathrm{g} / \mathrm{ml}$ and flocculation experiments in the presence of $8 \mathrm{mM}$ fructose and 0.5 $\mathrm{mM} \mathrm{KNO}_{3}$ were as previously described (Katupitiya et al. 1995a). Hydroxybutyrate in the flocculation experiments was used at the concentration of $20 \mathrm{mM}$ (Bleakley et al. 1988). Swarming was performed in semisolid minimal lactate medium containing $0.4 \%$ agar (Hall and Krieg 1983). Nitrogenase was assayed as previously described (Galimand et al. 1989). Transfer of plasmids into Azospirillum recipients was performed by conjugation with, in general, E. coli S17-1 as a donor, or, when the plasmids were contained in E. coli C600, by triparental mating with C600 containing plasmid pRK2013 as mobilizing agent, as previously described (Galimand et al. 1989). Tetracycline (Tc) was added at $5 \mu \mathrm{g} / \mathrm{ml}$ and kanamycin $(\mathrm{Km})$ at $20 \mu \mathrm{g} / \mathrm{ml}$ to culture media when required.

\section{Plant cultivation, in situ detection of bacteria colonizing the root surface, and assay for $\beta$-galactosidase activity.}

Wheat seeds (Triticum aestivum sp., spring cultivar Miskle) were germinated and grown in hydroponics under sterile conditions as described by Zeman et al. (1992). One-week-old plantlets were inoculated with $0.1 \mathrm{ml}$ of an overnight culture, approximately $5 \times 10^{6}$ bacterial cells per $\mathrm{ml}$ of hydroponics as described by Arsène et al. (1994). After 10 days, the colonization pattern of the root surface was examined by in situ staining of roots with 5-bromo-4-chloro-3-indolyl- $\beta$-Dgalactoside (X-Gal) as reported (Arsène et al. 1994) except that no treatment with sodium hypochlorite was performed. Determination of $\beta$-galactosidase activity on root extracts was performed according to Arsène et al. (1994). Results were expressed in Miller units per mg of plant soluble protein. Protein concentration was determined with BIO-RAD protein assay reagent.

\section{Construction of plasmid clones and DNA sequencing.}

Plasmid DNA isolation, restriction analysis, DNA hybridization, transformation, and molecular cloning were performed by conventional methods (Sambrook et al. 1989). The physical maps of the inserts of the plasmids constructed for this work are shown in Figure 1. Plasmids pAB1220-9a and pAB1220-9c were derived from pAB1220-9 after digestion by $B g l \mathrm{II}$ or $P s t \mathrm{I}$ and religation. Plasmid pAB1220-9b was derived from $\mathrm{pAB} 1220-9 \mathrm{a}$ after digestion by $P s t \mathrm{I}$ and religation. The 1.1-kb PstI fragment and the 4.6-kb Bam HI/BglII fragments were subcloned into pLA29.17 in both orientations to yield pAB2051 and -B or pAB2053 and -B, respectively. To perform $\mathrm{Tn} 5$ site-directed mutagenesis, the 9-kb HindIII fragment of pAB1220-9 was subcloned at the unique HindIII site of the suicide vehicle pSUP202 to yield pAB2000 (not shown). Different fragments from pAB1220-9 were cloned into the sequencing vector pTZ18R to yield pAB2060, -2061, and -2062, as depicted in Figure 1. From plasmid pAB2000 carrying insertions T1 and T4 (see below) it was possible to subclone a BamHI fragment carrying the aphII gene into pTZ18 by selection for $\mathrm{Km}$ resistance (not shown). The nucleotide sequences were performed on double-stranded DNA with the Taquence Kit (USB, Cleveland, OH), with appropriate oligonucleotides as primers. Tn5 flanking regions were established with the following primer: 5'-CCGTTCAGGACGCTACTT GTGTA-3'. Data were compiled with the Lasergene program. Similarity searches were made with the BLAST program of the National Center for Biotechnology Information Server.

\section{Tn5 mutagenesis.}

To mutagenize pAB1220-9a, it was introduced by transformation into E. coli S17.1-Tn5. Tn5-containing plasmids were first isolated after conjugation with $E$. coli C600 and selection on LB medium containing Rif, Tc, and $\mathrm{Km}$, and they were then transferred into A. brasilense $\mathrm{Sp} 7-\mathrm{S}$. Transconjugants that failed to complement Sp7-S for Congo red staining were tested for flocculation. This led to the identification of insertions T1, T2, and T4 (Fig. 1). Tn5 insertions that did not impair Congo red binding or flocculation were also mapped, as control (insertion T11 and T12; Fig. 1). The pAB1220-9 plasmid derivatives containing the Tn 5 insertions of interest (T1, T2, T4, T11, and T12) were then introduced by transformation into E. coli MC1061 containing pAB2000, in order to exchange the transposon from one plasmid to the other by homogenotization. The resulting plasmids were used to perform Tn5 site-directed mutagenesis of A. brasilense $\mathrm{Sp} 7$ genome as previously described (Galimand et al. 1989). It was verified by hybridization with appropriate DNA probes that the Tn5 had recombined at the correct location in the host genome as described previously (Galimand et al. 1989).

\section{Construction of a transcriptional lacZ fusion under the control of aphII gene promoter.}

The plasmid vector pLA29-17 carries a unique BlgII site and a unique PstI site in the kanamycin resistance gene (aphII). A lacZ-aphII cartridge purified from pKOK5 was in- 
serted as a BamHI or a PstI fragment into pAB2051 and pAB2053 so that the lac $Z$ gene would be under the control of the promoter of the kanamycin resistance gene of pLA29-17 in the resulting construction, named pAB2051Z and pAB2053Z, respectively.

\section{TEM.}

The medium used to prepare bacterial samples in the flocculation test was filtered on a $45-\mu$ m-pore membrane (Minisart, Sartorius AG, Göttingen, Germany) to remove precipitate and crystals in suspension prior to inoculation. Bacteria were fixed directly in culture flasks to obtain a final concentration of $2.5 \%$ glutaraldehyde in $0.1 \mathrm{M}$ cacodylate buffer, $\mathrm{pH}$ 7.5. The suspension was concentrated by low speed centrifugation, and the pellets of bacteria were washed with cacodylate buffer and post fixed with $2 \%$ osmium tetroxyde in the same buffer for $2 \mathrm{~h}$. Pellets were rinsed with water, then dehydrated with increasing ethanol series and embedded in Epon with Epoxy-1-2-propane as intermediate fluid. Thin sections were conventionally stained with uranyl acetate and lead citrate with a Jeol 1010 electron microscope operating under standard conditions.

\section{ACKNOWLEDGMENTS}

We wish to thank M. Schwartz for critical reading of the manuscript and J. P. Aubert, M. De Zamaroczy, and A. Kaminski for discussion while this work was in progress. We are grateful to J. Millet for her help in performing some experiments at the early stage of this work and to B. Chavinies-Javé for her capable technical assistance. L. P.-G. was the recipient of a fellowship form the Australian Research Council. This work was supported by research funds of the Australian Research Council, contract number A19330132.

\section{LITERATURE CITED}

Allen, L. L., and Hanson, R. S. 1985. Construction of broad host range cosmid cloning vectors: Identification of genes necessary for growth of Methylobacterium organophilum on methanol. J. Bacteriol. 161: 955-962.

Arsène, F., Katupitiya, S., Kennedy, I. R., and Elmerich, C. 1994. Use of lacZ fusions to study the expression of nif genes of Azospirillum brasilense in association with plants. Mol. Plant-Microbe Interact. 7: 748-757.

Baldani, V., Baldani, J., and Döbereiner, J. 1983. Effects of Azospirillum inoculation on root infection and nitrogen incorporation in wheat. Can. J. Microbiol. 29:924-929.

Bani, D., Barberio, C., Bazzicalupo, M., Favilli, F., Gallori, E., and Polsinelli, M. 1980. Isolation and characterization of glutamate synthase mutants of Azospirillum brasilense. J. Gen. Microbiol. 119:239244.

Bastarrachea, F., Zamudio, M., and Rivas, R. 1988. Non-encapsulated mutants of Azospirillum brasilense and Azospirillum lipoferum. Can. J. Microbiol. 34:24-29.

Bleakley, B. H., Gaskins, M. H., Hubbel, D. H., and Zam, S. G. 1988. Floc formation by Azospirillum lipoferum grown on poly- $\beta$-hydroxybutyrate. Appl. Environ. Microbiol. 54:2986-2995.

Casadaban, M., and Cohen, S. N. 1985. Analysis of gene control signals by DNA fusion and cloning in Escherichia coli. J. Mol. Biol. 138: 179-207.

Croes, C., Moens, S., Bastelaere, E. V., Vanderleyden, J., and Michiels, K. 1993. The polar flagellum mediates Azospirillum brasilense adsorption to wheat roots. J. Gen. Microbiol. 139:2261-2269.

de Zamaroczy, M., Paquelin, A., and Elmerich, C. 1993. Functional organization of the glnB-glnA cluster of Azospirillum brasilense. J. Bacteriol. 175:2507-2515.

Del Gallo, M., and Fendrik, I. 1994. The rhizosphere and Azospirillum. Pages 57-85 in: Azospirillum/Plant Associations. Y. Okon, ed. CRC
Press, Boca Raton, FL.

Del Gallo, M., Negi, M., and Neyra, C. A. 1989. Calcofluor- and lectinbinding exocellular polysaccharides of Azospirillum brasilense and Azospirillum lipoferum. J. Bacteriol. 171:3504-3510.

Dufrène Y. F., Vermeiren, H., Vanderleyden, J., and Rouxhet, G. 1996. Direct evidence for the involvement of extracellular proteins in the adhesion of Azospirillum brasilense. Microbiology 142:855-865.

Elmerich, C., Zimmer, W., and Vieille, C. 1992. Associative nitrogen fixing bacteria. Pages 212-258 in: Biological Nitrogen Fixation. G. Stacey, R. H. Burris, and H. Evans, eds. Chapman and Hall, New York.

Franche, C., and Elmerich, C. 1981. Physiological properties and plasmid content of several strains of Azospirillum brasilense and A. lipoferum. Ann. Inst. Pasteur Microbiol. 132A:3-17.

Galimand, M., Perroud, B., Delorme, F., Paquelin, A., Vieille, C., Bozouklian, H., and Elmerich, C. 1989. Identification of DNA regions homologous to nitrogen fixation genes nifE, nifUS and fixABC in Azospirillum brasilense Sp7. J. Gen. Microbiol. 135:1047-1059.

Gross, R., Aricò, B., and Rappuoli, R. 1989. Micro review: Families of bacterial signal-transducing proteins. Mol. Microbiol. 3:1661-1667.

Hall, P. G., and Krieg, N. R. 1983. Swarming of Azospirillum brasilense on solid media. Can. J. Microbiol. 29:1592-1594.

Henikoff, S. Wallace, J. C., and Brown, J. P. 1990. Finding protein similarities with nucleotide sequence databases. Methods Enzymol. 183:111-132.

Kahn, D., and Ditta, G. 1991. Modular structure of FixJ: Homology of the transcriptional activator domain with the -35 binding domain of sigma factors. Mol. Microbiol. 5:987-997.

Katupitiya, S., Millet, J., Vesk, M., Viccars, L., Zeman, A., Lidong, Z., Elmerich, C., and Kennedy, I. R. 1995a. A mutant of Azospirillum brasilense $\mathrm{Sp} 7$ impaired in flocculation with a modified colonization pattern and superior nitrogen fixation in association with wheat. Appl. Environ. Microbiol. 61:1987-1995.

Katupitiya, S., New, P. B., Elmerich, C., and Kennedy, I. R. 1995b. Improved $\mathrm{N}_{2}$ fixation in 2,4-D treated wheat roots associated with Azospirillum lipoferum: Studies of colonization using reporter genes. Soil Biol. Biochem. 27:447-452.

Kennedy, I. R., and Tchan, Y. T. 1992. Biological nitrogen fixation in non-leguminous field crops: Recent advances. Plant Soil 141:93-118.

Knauf, V. C., and Nester, E. V. 1982. Wide host range vectors: A cosmid clone bank of an Agrobacterium Ti plasmid. Plasmid 8:45-54.

Kokotek, W., and Lotz, W. 1989. Construction of a lacZ-kanamycinresistance cassette, useful for site-directed mutagenesis and as a promoter probe. Gene 84:467-471.

Michiels, K., Croes, C. L., and Vanderleyden, J. 1991. Two different modes of attachment of Azospirillum brasilense $\mathrm{Sp} 7$ to wheat roots. J. Gen. Microbiol. 137:2241-2246.

Michiels, K., De Troch, P., Onyeocha, I., Van Gool, A., Elmerich, C., and Vanderleyden, J. 1989a. Plasmid localization and mapping of two Azospirillum brasilense loci that affect exopolysaccharide synthesis. Plasmid 21:142-146.

Michiels, K., Vanderleyden, J., and Van Gool, A. 1989b. Azospirillum plant root associations: A review. Biol. Fertil. Soils 8:356-368.

Michiels, K., Verreth, C., and Vanderleyden, J. 1990. Azospirillum lipoferum and Azospirillum brasilense surface polysaccharide mutants that are affected in flocculation. J. Appl. Bacteriol. 69:705-711.

Moens, S., Michiels K., Keijers, V., Van Leuven F., and Vanderleyden, J. 1995. Cloning, sequencing, and phenotypic analysis of lafl, encoding the flagellin of lateral flagella of Azospirillum brasilense Sp7. J. Bacteriol. 177:5419-5426.

Msadek, T., Kunst, F., and Rapoport, G. 1993. Two-component regulatory systems. Pages 729-745 in: Bacillus subtilis and Other GramPositive Bacteria: Biochemistry, Physiology, and Molecular Genetics. A. L. Sonenshein, J. A. Hoch, and R. Losick, eds. American Society for Microbiology, Washington, DC.

Okon, Y. 1994. Azospirillum/Plant Associations. CRC Press, Boca Raton, FL.

Sadasivan, L., and Neyra, C. A. 1985. Flocculation in Azospirillum brasilense and Azospirillum lipoferum: Exopolysaccharides and cyst formation. J. Bacteriol. 163:716-723.

Sadasivan, L., and Neyra, C. A. 1987. Cyst production and brown pigment formation in aging cultures of Azospirillum brasilense ATCC29145. J. Bacteriol. 169:1670-1677.

Sambrook, J., Fritsch, E. F., and Maniatis, T. A. 1989. Molecular Clon- 
ing: A Laboratory Manual. 2nd ed. Cold Spring Harbor Laboratory, Cold Spring Harbor, NY.

Schweizer, H. P. 1991. The agmR gene, an environmentally responsive gene, complements defective $g l p R$, which encodes the putative activator for glycerol metabolism in Pseudomonas aeruginosa. J. Bacteriol. 173:6798-6806.

Simon, R., Priefer, U., and Pühler, A. 1983. A broad host range mobilization system for in vivo genetic engineering: Transposon mutagenesis in Gram-negative bacteria. Biotechnology 1:784-791.

Stout, V., and Gottesman, S. 1990. RcsB and RcsC: A two-component regulator of capsule synthesis in Escherichia coli. J. Bacteriol. 172: 659-669.

Stock, J. B., Ninfa, A. J., and Stock, A. M. 1989. Protein phosphorylation and regulation of adaptive responses in bacteria. Microbiol. Rev. 53:450-490.

Swift, S., Winson, M. K., Chan, P. F., Bainton, N. J., Birrdsall, M., Reeves, P. J., Rees, C. E. D., Chhabra, S. R., Hill, P. J., Thoup, J. P., Bycroft, B. W., Salmond, G. P. C., Williams, P., and Stewart, G. S. A. B. 1993. A novel strategy for the isolation of LuxI homologues: Evidence for the widespread distribution of a LuxR:LuxI superfamily in enteric bacteria. Mol. Microbiol. 10:511-520.0
Tarrand, J. J., Krieg, N. R., and Döbereiner, J. 1978. A taxonomic study of the Spirillum lipoferum group with description a new genus, Azospirillum gen. and two species, Azospirillum lipoferum (Beijerinck) comb. nov. and Azospirillum brasilense sp. nov. Can. J. Microbiol. 24:967-980.

Vande Broek, A., Michiels, J., Van Gool, A., and Vanderleyden, J. 1993. Spatial-temporal colonization patterns of Azospirillum brasilense on the wheat root surface and expression of the bacterial nifH gene during association. Mol. Plant-Microbe Interact. 6:592-600.

Vande Broek, A., and Vanderleyden, J. 1995. Review: Genetics of the Azospirillum-plant root association. Crit. Rev. Plant Sci. 14:445466.

Zeman, A. M. M., Tchan, Y. T., Elmerich, C., and Kennedy, I. R. 1992. Nitrogenase activity in wheat seedlings bearing para-nodules induced by 2,4-dichlorophenoxyacetic acid (2,4-D) and inoculated with Azospirillum. Res. Microbiol. 143:847-855.

Zimmer, W., Kloos, K., Hundeshagen, B., and Bothe, H. 1995. Auxin biosynthesis and denitrification in plant growth promoting bacteria Pages 108-128 in: Azospirillum VI and Related Microorganisms. Nato ASI Series, Vol. G 37. I. Fendrik, M. del Gallo, J. Vanderleyden, and M. de Zamaroczy, eds. Springer Verlag, Berlin. 